\title{
Efektivitas Kelompok Wanita Tani Lestari Di Desa Subun Tua'lele Kecamatan Insana Barat Kabupaten Timor Tengah Utara
}

\author{
Anna Cisca Da Costa ${ }^{a}$, Marsianus Falo ${ }^{b}$, Agustinus Nubatonis ${ }^{c}$ \\ ${ }^{a}$ Fakultas Pertanian, Universitas Timor, Kefamenanu, TTU - NTT, 85613, Indonesia.

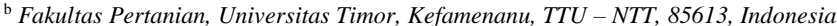 \\ ${ }^{\mathrm{c}}$ Fakultas Pertanian, Universitas Timor, Kefamenanu, TTU - NTT, 85613, Indonesia.
}

\section{Article Info}

\section{Article history:}

Received 27 Maret 2016

Received in revised form 4 April 2016

Accepted 11 April 2016

\section{Keywords:}

Efektivitas

Wanita Tani Lestari

Subun Tua'lele

Insana Barat

\begin{abstract}
Abstrak
Pemberdayaan kelompok tani merupakan upaya yang harus dilakukan untuk meningkatkan produktivitas kelompok tani tersebut yang akan berdampak pada kesejahteraan masyarakat atau anggota kelompok tani tersebut. Tujuan penelitian ini adalah untuk mengetahui gambaran Kelompok Wanita Tani Lestari, Desa Subun Tua'lele, Kecamatan Insana Barat dan untuk mengkaji faktor-faktor yang berhubungan dengan faktor pembentuk efektivitas kelompok tani di Kelompok Wani Tani Lestari, Desa Subun Tua'lele, Kecamatan Insana Barat.Penelitian in dilaksanakn dari bulan Desember-Januari. Metode yang digunakan dalam penelitian ini adalah metode statistik deskriptif. Sedangkan teknik atau cara analisa data yang relevan digunakan dalam penelitian ini adalah teknik rank spearman yang digunakan untuk menganalisa hubungan antara faktor pembentuk efektivitas kelompok tani dengan efektivitas kelompok tani. Hasil penelitian menunjukkan bahwa bahwa tingkat efektivitas wanita tani lestari berada pada kategori sedang. Faktor penyebab umum yang dapat dilihat adalah karena sedikitnya bahan yang digunakan untuk produksi dan rendahnya kualitas sumber daya manusia dalam pengolahan pasca panen sehingga tidak mendatangkan hasil yang banyak. Oleh karena itu diperlukan upaya yang lebih maksimal untuk meningkatkan produktivitas pengolahan pasca panen.Hasil analisis rank spearman juga menunjukkan bahwa terdapat hubungan yang signifikan antara faktor pembentuk efektivitas kelompok tani dengan efektivitas kelompok tani di desa Subun Tua'lele Kecamatan Insana Barat. (02016 dipublikasikan oleh Agrimor.
\end{abstract}

\section{Pendahuluan}

Pemberdayaan masyarakat lewat kelembagaan kelompok tani secara optimal merupakan salah satu program pemerintah lewat Departemen Pertanian yang kebijakannya dilakukan melalui pemberian pelatihan dan keterampilan bagi penyuluh pertanian; pelaksanaan penyuluhan dan latihan bagi petani melalui kelompok tani maupun perorangan; dan memberikan motivasi bagi penguatan kelembagaan petani ke arah kemandirian kelompok, ketangguhan kelompok, dan kemitraan usaha. Tujuan yang hendak dicapai adalah peningkatan sumber daya pelaku usaha pertanian menjadi sumber daya yang tangguh, terampil, dan mandiri; optimalisasi pemanfaatan sumber daya yang dapat memberikan nilai tambah melalui penerapan teknologi dan berwawasan lingkungan; meningkatan pelayanan di bidang pertanian; dan memantapkan kelembagaan tani melalui pembinaan dan peningkatan kelas kemampuan kelompok tani (Mardikanto T. 1993).

Pemberdayaan kelompok tani ini dilaksanakan hampir di semua daerah termasuk Kabupaten Timor Tengah Utara. Kabupaten Timor Tengah Utara memiliki 1.233 Kelompok tani yang terdiri dari kelas pemula 1.172 Kelompok tani, kelas lanjut 60 kelompok tani, dan kelas madya 1 kelompok tani, tani yang bergerak dalam luasan wilayah Kabupaten Timor Tengah Utara 2669,70 km². (Databes numerik Kab. TTU 2013).

Kecamatan Insana Barat merupakan salah satu wilayah yang berada di Kabupaten Timor Tengah Utara yang memiliki luas wilayah lahan tanam 10.273 Ha dengan luas panen 10.273 dan produksi 103.131 ton (BPS TTU, 2014). Keadaan kelompok tani di Kecamatan Insana barat, dari 77 kelompok tani, terdapat 24 kelompok tani dengan kelas pemula, 3 kelompok tani dengan kelas lanjut dan 50 kelompok tani dengan kelas pra pemula sedangkan kelompok tani dengan kelas madya dan kelompok tani dengan kelas utama belum ada.

Desa Subun Tua'lele merupakan salah satu desa yang petaninya tergabung dalam kelompok tani. Dimana terdapat dua kelas kelompok yaitu kelompok tani madya yang berjumlah 2 kelompok tani dan kelompok tani pemula yang berjumlah 3 kelompok tani. Kelas kelompok tani ini menunjukkan bahwa kelompok tani di Desa Subun Tua'leletelah berjalan dengan baik, untuk itu peneliti ingin mengetahui bagaimana tingkat efektivitas di sana. Disamping di Desa Subun Tua'lele setiap kelompok tani memiliki jumlah anggota yang cukup banyak, sehingga akan mempengaruhi tingkat efektivitas kelompok tani itu sendiri. Untuk itu perlu diadakan penelitian tentang efektivitas kelompok Wanita Tani Lestari di Desa Subun Tua'lele.

Kelompok Wanita Tani Lestari merupakan wadah berkumpulnya segenap wanita tani yang memiliki lahan pertanian/perkebunan yang masih belum maksimal pengolahannya karena kurangnya produktivitas antar anggota kelompok dalam pengolahan hasil pertanian dan kurangnya sarana dan prasaran.

Kelompok Wanita Tani Lestari juga membuat agenda sebagai acuan aga program yang dibuat dapat terencana dan terarah sesuai dengan visi-misi dan tujuan yang diharapkan, yaitu: melakukan kegiatan pertemuan rutin sekali dalam sebulan, pembentukan koperasi yang sehat, penelitian dan inovasi dalam pertanian dan perkebunan, berkordinasi dengan dinas terkait baik kabupaten maupun provinsi agar diberikan pembinaan, keterlibatan dalam GAPOKTAN dan mendukung program pemerintah.

Efektivitas merupakan hal yang penting bagi satu organisasi, karena dengan adanya efektivitas tujuan kelompok tani dapat tercapai. Efektivitas dalam kelompok tani digunakan untuk menganalisa tujuan-tujuan kelompok ataupun tujuan anggota yang belum tercapai sehingga perencanaan kegiatan kelompok akan berjalan kearah yang lebih produktif dan efektif (Kusnadi, 2006).

Dengan demikian maka Wanita Tani Lestari Desa Subun Tua'lele sebagai salah satu kelembagaan tani perlu diberdayakan agar menjadi kelembagaaan tani yang kuat, mandiri, dan dapat menjadi efektif. Untuk mencapai keefektifan kelompok tani tidak terlepas dari faktor-faktor yang mempengaruhinya.

\section{Metode}

Data yang digunakan dalam penelitian ini adalah data primer dan sekunder. Metode Penentuan Sampel. Sampel yang digunakan dalam penelitian in sebanyak 20 responden. Pengambilan sampel dilakukan dengan teknik acak kelompok (multistage cluster random sampling). Analisis data yang digunakan dalam penelitian ini adalah analisis statistik deskriptif. Untuk menganalisis hubungan antara faktor pembentuk efektivitas kelompok tani dengan efektivitas kelompok tani digunakan rumus Korelasi Rank Spearman (Priyatno, 2013).

\section{Hasil dan Pembahasan}

\subsection{Efektifitas Kelompok Wanita Tani Lestari}

Untuk mengetahui faktor-faktor yang mempengaruhi efektivitas kelompok tani maka terlebih dahulu harus diketahui tentang efektivitas kelompok tani itu sendiri. Berbicara tentang efektivitas kelompok tani maka berbicara tentang keberhasilan kelompok untuk mencapai tujuannya yang ditunjukkan dengan tercapainya keadaan atau kondisi yang dinginkan baik secara fisik maupun non fisik. Efektivitas kelompok juga dapat dipahami sebagai tercapainya tujuan kelompok sesuai dengan kebutuhan yang direncanakan. Dalam penelitian ini indikator yang digunakan untuk mengukur efektivitas adalah produktivitas dan kepuasan anggota.

Tabel 1. Tingkat efektivitas kelompok wanita tani Lestari

\begin{tabular}{ccccc}
\hline No & Indikator & Kategori & Jumlah & Prosentase (\%) \\
\hline 1 & Produktivitas & Tinggi & 3 & 15 \\
& & Sedang & 11 & 55 \\
& Rendah & 6 & 30 \\
\hline \multirow{2}{*}{2} & Kepuasan & Tinggi & 3 & 15 \\
& & Sedang & 11 & 55 \\
& & Rendah & 6 & 30 \\
\hline
\end{tabular}

Sumber: data primer (diolah) 2016

Berdasarkan hasil penelitian di atas, tampak bahwa tingkat efektivitas wanita tani lestari berada pada kategori sedang. Hal ini terlihat dari jawaban yang diberikan oleh responden sebanyak 20 orang. Pada indikator produktivitas, jumlah responden yang memberikan jawaban pada kategori sedang berjumlah 11 orang. Hal ini menunjukkan bahwa tingkat produktivitas pengolahan pasca panen belum berjalan secara maksimal sehingga produktivitasnya juga berkurang. Faktor penyebab umum yang dapat dilihat adalah karena sedikitnya bahan yang digunakan untuk produksi dan rendahnya kualitas sumber daya manusia dalam pengolahan pasca panen sehingga tidak mendatangkan hasil yang banyak.

Sedangkan pada indikator kepuasan, rata-rata tingkat kepuasan anggota kelompok wanita tani lestari berada pada kategori sedang bahkan rendah. Indikator kepuasan ini sangat berkaitan dengan indikator produktivitas. Apabila produktivitas pengolahan pasca panen tinggi maka dengan sendirinya indikator kepuasan akan tinggi. Sebaliknya, apabila produktivitasnya menurun atau rendah maka tingkat kepuasan juga akan rendah. Hasil penelitian menunjukkan bahwa banyak anggota kelompok wanita tani lestari yang tidak puas dengan hasil yang diperoleh. Oleh karena itu diperlukan upaya yang lebih maksimal untuk meningkatkan produktivitas pengolahan pasca panen

Kategori sedang dari efektivitas kelompok wanita tani lestari disebabkan oleh beberapa faktor, yakni faktor ciri kelompok yang terdiri dari kepemimpinan, kekompakan dan intensitas pertemuan, faktor fungsi tugas dan faktor luar kelompok yang terdiri dari dukungan pemimpin formal dan pemimpin informal. 
3.2 Faktor-faktor Yang Mempengaruhi Efektivitas Kelompok Wanita Tani Lestari

Berdasarkan hasil penelitian, di atas faktor-faktor yang mempengaruhi efektivitas kelompok wanita tani Lestari. Hasil penelitian juga menunjukkan bahwa efektivitas kelompok wanita tani lestari masih berada pada kategori sedang. Berikut adalah data hasil penelitian pada kelompok tani lestari di Desa Subun Tua'lele menurut ukuran tingkat efektivitas kelompok.

Tabel 2. Faktor-faktor Yang Mempengaruhi Efektivitas Kelompok Wanita Tani

\begin{tabular}{ccccc}
\hline Variabel & Kategori & Skor & Jumlah Anggota & Persentasi (\%) \\
\hline \multirow{2}{*}{ Ciri } & Tinggi & $7-9$ & 4 & 20 \\
Kelompok & Sedang & $4-6$ & 14 & 70 \\
& Rendah & $1-3$ & 2 & 10 \\
\hline Jumlah & & & 20 & 100 \\
\hline \multirow{5}{*}{ Fungsi Tugas } & Tinggi & $13-$ & 6 & 30 \\
& & 18 & & 60 \\
& Sedang & $7-12$ & 12 & 10 \\
\hline Jumlah & Rendah & $1-6$ & 2 & 100 \\
\hline \multirow{2}{*}{ Luar } & Tinggi & $5-6$ & 10 & 50 \\
kelompok & Sedang & $3-4$ & 8 & 40 \\
\hline Jumlah & Rendah & $1-2$ & 2 & 10 \\
\hline
\end{tabular}

Sumber: data primer (diolah) 2016

Hasil penelitian yang disajikan pada tabel di atas menunjukkan bahwa variabel ciri kelompok yang di dalamnya mencakup aspek kepemimpinan, kekompakan dan intensitas pertemuan pada kelompok wanita tani lestari berada pada kategori sedang. Dari total 20 responden, 14 orang anggota menjawab pada kategori sedang. Hal ini menunjukkan bahwa ketiga aspek ini belum berjalan secara maksimal. Berdasarkan data hasil penelitian, faktor kekompakan sering menjadi masalah karena banyaknya kesibukan dari para ibu rumah tangga sehingga agak kesulitan dalam membagi waktu antara bekerja dan mengurus rumah tangga. Sedangkan aspek kepemimpinan tidak menjadi masalah karena ketua kelompok tani dipilih secara langsung melalui musyawarah. Kemudian, jarak tempat tinggal yang berdekatan juga memberikan kuntungan kepada pemimpin karena lebih mudah mengakomodir persoalan dan upaya penyelesaian persoalan yang ditemukan.

Sedangkan terkait fungsi tugas kelompok tani, berdasarkan hasil penelitian masuk dalam kategori sedang. Fungsi tugas kelompok tani ini adalah memberi informasi, memuaskan anggota, menyelenggarakan koordinasi, menghasilkan inisiatif, mengajak berperan serta dan menjelaskan. Fungsi kelompok tani masuk dalam kategori sedang karena dalam banyak hal kelompok tani mampu menyampaikan dan menjelaskan informasi kepada anggotanya, mampu menyelenggarakan koordinasi, mampu mengajak dan mengumpulkan semua anggotanya untuk berpartisipasi dalam pelaksanaan kegiatan kelompok Tani serta mampu memberikan penjelasn kepada semua anggota kelompok tani. Namun terkait fungsi menghasilkan, hanya sebagian kecil anggota kelompok yang bisa melakukan itu karena kurangnya pemahaman dan kurangya akses untuk mendapatkan kebutuhan sarana produksi.

Terkait faktor luar kelompok yang terdiri dari dukungan pemimpin baik formal maupun informal dan kondisi fisik lokasi kelompok masuk dalam kategori tinggi. Hal ini terjadi karena pembentukan kelompok wanita tani lestari sejak awal mendapat dukungan dari pemerintah desa sebab sejalan dengan upaya pemerintah desa untuk memberdayakan masyarakat desa dan meningkatkan kesejahteraan masyarakat desa. Selain itu, kelompok wanita tani lestari juga sejak awal pembentukan dan dalam proses perkembangannya selalu membangun kerja sama dengan banyak LSM dan dinas terkait.

\subsection{Analisis Hubungan Antar Variabel}

Analisis hubungan antar variabel dilakukan dengan uji korelasi rank Spearmen untuk mengetahui tingkat tingkat signifikansi dengan menggunakan uji t- pada tingkat kepercayaan 95\%. Uji korelasi Spearman dengan SPSS pada hakikatnya serupa dengan secara manual. Uji korelasi Spearman adalah uji statistik yang ditujukan untuk mengetahui hubungan antara dua atau lebih variabel berskala Ordinal.

Berdasatkan Tabel 3. dapat dilihat hubungan antar variabel penelitian pada taraf kepercayaan $95 \%$ dengan menggunakan analisis SPSS. Hubungan antara faktor-faktor yang mempengaruhi efektivitas kelompok tani dengan produktivitas kelompok wanita tani Lestari dapat dijelaskan sebagai berikut.

Variabel X1 merupakan faktor ciri kelompok yang terdiri dari kepemimpinan, kekompakan dan intesitas kelompok. Berdasarkan hasil analisis data di atas tampak bahwa nilai t hitung adalah 0,988 dan nilai ini lebih besar dari nilai t tabel $(0,05)$. Hal ini menunjukkan bahwa ada hubungan yang signifikan antara faktor pembentuk efektivitas kelompok tani yang dalam hal ini adalah faktor ciri kelompok dengan efektivitas kelompok tani di desa Subun Tua'lele Kecamatan Insana Barat. Efektivitas kelompok tani yang tercermin dalam produktivitas akan menunjukkan hasil baik apabila terdapat kepemimpinan kuat yang mampu memberikan motivasi dan teladan yang baik dalam bekerja

Variabel X2 merupakan faktor fungsi atau tugas kelompok yang terdiri dari fungsi memberi informasi, fungsi memuaskan anggota, fungsi membangun koordinasi, fungsi inisiatif, berperan serta dan fungsi menjelaskan. Berdasarkan hasil analisis data di atas tampak bahwa nilai t hitung adalah 0,659 dan nilai ini lebih besar dari nilai t tabel $(0,05)$. Hal ini menunjukkan bahwa ada hubungan yang signifikan antara faktor fungsi atau tugas kelompok dengan efektivitas kelompok tani di desa Subun Tua'lele Kecamatan Insana Barat. Agar kelompok wanita tani Lestari semakin efektif maka diperlukan fungsi-fungsi di atas. Semua anggota kelompok harus mendapat informasi yang baik tentang kegiatan yang dilaksanakan sehingga hasil yang diharapkanpun dapat tercapai. Semakin tinggi fungsi tugas yang dilakukan oleh kelompok tani maka semakin tinggi produktivitas. Dari data penelitian tampak bahwa para petani merasa puas karena memperoleh informasi yang dapat dipahami sehingga menambah pengetahuan mereka. Selain itu mereka juga dapat berkoordinasi dengan anggota lain dan mampu mengajak anggota lain untuk berperan serta dalam pelaksanaan kegiatan kelompok tani.

Tabel 3. Analisis Hubungan Antar Variabel

\begin{tabular}{|c|c|c|c|c|c|c|}
\hline & & & $\mathrm{X} 1$ & $\mathrm{X} 2$ & $\mathrm{X} 3$ & $\mathrm{Y}$ \\
\hline \multirow{12}{*}{ 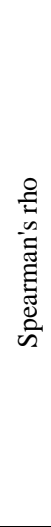 } & \multirow[t]{3}{*}{$\mathrm{X} 1$} & Correlation Coefficient & 1.000 & -.007 & .118 & .004 \\
\hline & & Sig. (2-tailed) & & .976 & .619 & .988 \\
\hline & & $\mathrm{N}$ & 20 & 20 & 20 & 20 \\
\hline & \multirow[t]{3}{*}{$\mathrm{X} 2$} & Correlation Coefficient & -.007 & 1.000 & -.109 & -.105 \\
\hline & & Sig. (2-tailed) & .976 & & .648 & .659 \\
\hline & & $\mathrm{N}$ & 20 & 20 & 20 & 20 \\
\hline & \multirow[t]{3}{*}{ X3 } & Correlation Coefficient & .118 & -.109 & 1.000 & .063 \\
\hline & & \begin{tabular}{|l|} 
Sig. (2-tailed) \\
\end{tabular} & .619 & .648 & & .793 \\
\hline & & $\mathrm{N}$ & 20 & 20 & 20 & 20 \\
\hline & \multirow[t]{3}{*}{ Y } & Correlation Coefficient & .004 & -.105 & .063 & 1.000 \\
\hline & & Sig. (2-tailed) & .988 & .659 & .793 & \\
\hline & & $\mathrm{N}$ & 20 & 20 & 20 & 20 \\
\hline
\end{tabular}

Sumber: data primer (diolah) 2016 menggunakan SPSS

Variabel X3 merupakan faktor luar kelompok yang terdiri dari dukungan pemimpin baik pemimpin formal maupun informal dan kondisi fisik lokasi. Berdasarkan hasil analisis data di atas tampak bahwa nilai t hitung adalah 0,793 dan nilai ini lebih besar dari nilai t tabel $(0,05)$. Hal ini menunjukkan bahwa ada hubungan yang signifikan antara faktor luar kelompok dengan efektivitas kelompok tani di desa Subun Tua'lele Kecamatan Insana Barat. Keberadaan kelompok wanita tani Lestari tidaklah terlepas dari dukungan yang diberikan baik oleh pemerintah desa maupun oleh lembaga-lembaga lain. Karena itu, agar dapat berkelanjutan maka kelompok wanita tani harus selalu membangun koordinasi dengan pihak-pihak tersebut terutama dalam kaitannya dengan penguatan kapasitas sumber daya manusia melalui pelatihan-pelatihan mapun diklat untuk memberikan pemahaman baru kepadaa anggota kelompok. Hal ini dimaksudkan untuk lebih meningkatkan efektivitas kelompok wanita tani Lestari.

\section{Simpulan}

Kelompok wanita tani lestari merupakan salah satu kelompok tani yang berada dalam wilayah Desa Subun Tua'lele Kecamatan Insana Barat yang dibentuk pada tahun 2000. Kelompok wanita tani lestari juga merupakan satusatunya kelompok yang semua anggotanya terdiri dari para wanita yang terdorong oleh keinginan untuk lebih mensejahterahkan hidup melalui pengelolaan pertanian pertanian. Nama kelompok Wanita Tani Lestari dipilih karena selain beranggotakan para ibu, kelompok ini juga dimaksudkan untuk mampu merubah hidup para ibu pada khususnya dan keluarga pada umumnya agar menjadi lebih lestari. Berdasarkan hasil penelitian di atas, tampak bahwa tingkat efektivitas wanita tani lestari berada pada kategori sedang. Faktor penyebab umum yang dapat dilihat adalah karena sedikitnya bahan yang digunakan untuk produksi dan rendahnya kualitas sumber daya manusia dalam pengolahan pasca panen sehingga tidak mendatangkan hasil yang banyak. Oleh karena itu diperlukan upaya yang lebih maksimal untuk meningkatkan produktivitas pengolahan pasca panen. Kategori sedang dari efektivitas kelompok wanita tani lestari disebabkan oleh beberapa faktor, yakni faktor ciri kelompok yang terdiri dari kepemimpinan, kekompakan dan intensitas pertemuan, faktor fungsi tugas dan faktor luar kelompok yang terdiri dari dukungan pemimpin formal dan pemimpin informal. Hubungan antara faktorfaktor yang mempengaruhi efektivitas kelompok tani dengan produktivitas kelompok wanita tani Lestari dengan analisis rank speraman antara lain 1) Terdapat hubungan yang signifikan antara faktor pembentuk efektivitas kelompok tani yang dalam hal ini adalah faktor ciri kelompok dengan efektivitas kelompok tani di desa Subun Tua'lele Kecamatan Insana Barat; 2) Terdapat hubungan yang signifikan antara faktor fungsi atau tugas kelompok dengan efektivitas kelompok tani di desa Subun Tua'lele Kecamatan Insana Barat; 3) Terdapat hubungan yang signifikan antara faktor luar kelompok dengan efektivitas kelompok tani di desa Subun Tua'lele Kecamatan Insana Barat. 
Pustaka

BPS Timor Tengah Utara 2014. Badan Pusat Statistik Kabupaten Timor Tengah Utara.

Ban Van den AW, HS Hawkins. 1999. Penyuluhan Pertanian. Jakarta

Database Numerik Kabupaten TTU Tahun 2013

Kusnadi, Dedy. 2006. Kepemimpinan Kelompok Tani Dalam Meningkatkan Efektivitas Kelompok Tani. Jurnal Penyuluhan Pertanian Vol.1 No.1,Mei 2006

Mardikanto T.1993. Penyuluhan Pembangunan Pertanian. Surakarta http://www.foxitsoftware.com For evaluation only.

Duwi Prayitno 2013. Analisi Korelasi, Regresi dan Multivariate dengan SPSS. Penerbit Gava Media. Yogyakarta 